\title{
The Personal Computer: A Hot Rod for the Mind . Paul Mace
}

“DO IT, ,' SHE SAYS, FLATLY, "and I'll leave you," an ultimatum she has delivered only once before in ten years of marriage. A handsome woman with long hair and a face that shapes most naturally for a smile, she scowls and bites deeply into the middle of her sandwich. I divide my own, sending each of the children away with a quarter.

"It's really simple." Wiping her mouth without erasing the disapproval, she continues, "That's the problem. I don't really feel I have to explain. It should be obvious; you're obsessed. Even when you're not reading about it, you're thinking about it. It's all you want to talk about. It's true! Put your hand down. I admit, I don't understand half or a quarter of what you're saying. It's not the first time. I still don't really understand how my car works, or electricity, or the atomic bomb, but I don't feel compelled to. I can live with what I already know about those things. I know what I think. But not you. I don't think there is anything you could resist looking into, except, on occasion, your own motives. Usually I can stand that part of you. You drag me along, I learn things, I'm grateful, I like to learn things I can use. I just don't want to learn about this."

It is characteristic of the sort of democracy our generation has brought to the institution of marriage that unless she learns enough to approve or disapprove intelligently of the plan, events cannot move forward. Suffrage leads us not towards chaos, rather into suspended animation. I find myself holding my thumb inside my fist, determined to explain.

It is $\mathbf{x x}$ by $\mathbf{x x}$ by $\mathbf{x x}$ and weighs $\mathbf{x . x}$ pounds. It has a detachable keyboard you can hold in your lap, produces a full ASCII character set, upper-and lower-case, has ten special-function keys and comes in one color, off-white. It has a four-megaherz clock, RS232C asynchronous adapter, dual floppy disks, sixteen-color, high-resolution graphics capabilities, forty kilobytes of Read-only memory (ROM), five hundred twelve kilobytes of Random-access memory (RAM) and costs just under sixteen hundred dollars-or would if you could disregard the treacherous little dagger + aiming your attention to the bottom of the page and the fine print: Not as pictured. 
The accompanying text allows, "It is not an unusual phenomenon. It starts when your son asks to borrow a tie. Or when your daughter wants to use your metal racquet. Sometimes you let them. Often you don't. But when they start asking to use your...." Not a car-Detroit abandoned this sort of advertising twenty years ago when it became apparent fathers no longer controlled anything but their ties and their tennis racquets. A happy young man with a shag haircut, even smile and a football jersey is shown leaning on what looks like some sort of radio with a typewriter keyboard where the microphone should be. Also depicted is a small portable television with a few illegible green lines of print. There is something perhaps suggestive of automobiles; whatever the thing is, where you would expect to see knobs and switches there is only a black mask, one of those enigmatic electronic displays found on the instrument panels and tail ends of sportier cars and designed to conceal certain warnings and hazards unless and until they actually occur. Concessions to the accidental nature of the Universe that cannot be masked or filleted with plastic (like bumpers on certain inexpensive makes) are painted, to lessen the shock of contrast. Here the manufacturer's logo, in bas-relief on each component, is unreadable.

From where we sit at her desk I can see beyond my wife fifty or so cubicles spaced around the sort of 'open plan' area favored by colleges and other smokeless industries, who have come in these fluid times to eschew dedicating any 'available space' to a 'permanent use.' Like single quotes used to separate vogue concepts from common meaning, a pair of movable screens defines each 'work station' in this otherwise seamless, carpeted plane. In terms of traditional architecture, where we sit is nothing more than an open pavilion. The walls that enclose us bear no load, the ceiling is false, the lighting on tracks-nothing, it has been demonstrated, one man with a hammer and a screwdriver could not redescribe in totally different fashion between, say, five one Friday afternoon and eight next Monday morning. The only limits are those set by certain cables and conduits imbedded in the slab and through which each work station is connected to lines of information and power. Each individual space is wired for tape, televsion and a half-dozen assorted machines of less advanced technology designed to aid self-paced learning. Somewhere in the back, in a room of its own, although I have never seen it, I know there is a computer.

"I've used it," she says. "It's all right, I suppose, but I've left it to the others. They aren't happy about that. I've broken ranks. It's more like 
I've broken faith, which is very hard to tolerate in a place where we have to work so closely together without any real privacy. I'm not a technophobe. I'm not sure what I am. Machines don't scare me; I'm just not a friend of our electronic friend. Not that they mind. I think they'd both rather work with the computer than out here, with the people. That's what ticks me off. Why else are we here? When the machines fail, who can the students come to? It's not even the machines-you know, the people we deal with here are not geniuses, they are people with problems, learning problems, personal problems. The two go together, people and problems. You don't find one without the other. Sometimes I can resolve them. Mostly I can tell people it's all right, they're trying, they're making some progress. You can't get that out of a machine."

"You can."

"You can, but it has no meaning. It's publicity, like a road sign. Everybody gets the same message. The sign doesn't believe in you. The machine that prints the sign does not know you. For all they care"pointing at the machines-"you could be some ape from Behavioral Science trying to get a banana."

The computer appears to pose as great a threat to our concept of humanity as Darwin's theory did to Man's image of God. Having seen the simian face of the Creator, we could no longer take Him seriously. Now, encountering the machine-face of intelligence, we can no longer take ourselves seriously, or at least regard that unprojected portion of ourselves into which we have been retreating for the last hundred years, the 'rational animal,' with the same old awe and respect.

Still, it is a chilling absurdity, the image of the ape at the keyboard being encouraged by a machine with consummate patience to try again. Where are we now? Man, some pavilion of hair and bones, his 'nature' no longer infinitely variable but tethered to the limits of his language, appears to be running out of space between quotes in which to define himself. He is getting right down to the naked 'I,' the poignantly tragic and cosmically ephemeral assertion he exists.

Despite all this, I am unable to escape my own feeling that whoever placed this and other advertisements for similar products has me specifically, individually in mind. The letters IBM recurrent in the text carry a weight of personal meaning I find difficult to ignore or, at first, elaborate. I feel I am being offered something profound, something one step beyond: the counterforce! the anti-computer computer! My ma- 
chine and their machine will hash it all out safely, high overhead, at the apex of some data-link where the conflict poses no danger to human life. With my personal computer will come a new balance of poweralbeit, the same sort promised by the sale of sophisticated weaponry to Pakistan, the individual in the position of the industrially backward nation, defending himself at a level of sophistication it is not clear he can afford or sustain, but in any case being offered the chance. Who is to say no? A foolish strategy, but what other strategy is there? To regress? To wait until the electronic onslaught is so far advanced that we are effectively ignorant as apes in the face of our own civilization? Our good fortune that the same material self-interest which set things in a ferment to begin with, leaving dad in full possession of his cravat, his magnesium racquet, his commute vehicle and his time in which to wonder how and where exactly the rest of life got away from him, now proposes a reversal of that trend. Like the Imperial nations following World War II, parents, precipitous in bestowing democracy, in allowing their children to come into possession of their own cars, their own drugs, their own sex, are now offered the opportunity to make this final concession and bring things full circle. Contained within this ad is the promise of the restoration of the center, the nucleus of the family, Man as the ultimate figure of authority. Even if you have never ridden, or drivenor inputted and outputted-any form of computer, at $\$ 1600$, it would be a stellar bargain. Control! IBM is offering control-IBM, with whose initials control in the minds of the world and, until recently, the U.S. Department of Justice, was synonymous-wants to sell us control for sixteen hundred dollars, wants to put us back in the pilot's seat, if not of our soul, exactly, at least of our daily affairs. IBM, perhaps the most singularly American, Capitalist and smokeless of industrial giants, is proposing to finalize a counter-revolution begun early this century with the introduction of the Model $\mathrm{T}$, to make the machine not an inescapable enemy of the people, as Marx saw it, but an inestimable ally. All for a mere sixteen hundred dollars; slightly more than the cost of a home video recorder and considerably less than any automobile-nothing costs sixteen hundred dollars-or twenty-six, or even thirty-six hundred. Due to advances in technology, we are being offered the chance to reestablish ourselves in the driver's seat at the same level of exchange as when that position was lost by our parents in the late fifties as Detroit, having saturated the market for the second time in a decade, began to undercut its old customers by dealing directly with children. Sixteen hundred 
dollars is in fact what I agreed to pay the local Plymouth dealer for freedom in 1964.

"Stop," she says. "I want you to promise me one thing. Before you buy anything, call me."

Jimmy Carter has one (not an IBM, a loaner from Lanier) and, shades of Rosemary Woods, accidentally erased a page of memoir punching the wrong button. Dick Cavett has one (Apple) and so do William Shatner (Commodore) and Bill Cosby (Texas Instruments). One gets the inescapable feeling while watching their commercials that, unlike Bruce Jenner touting Wheaties or George Steinbrenner Lite beer, these men find the experience enriching beyond what they are paid for their commercial endorsements. Men of candor, humor, foresight-Shatner someone who has not merely seen the future, but been there-men of recognizable intelligence, they convey a feeling of ease and familiarity with what to people like my wife is still a foreign subject. That is their talent, Cavett with celebrity, Cosby with Blacks, Shatner as Captain Kirk in endless reruns of Star Trek with extraterrestrial life ("I don't know, Spock, they seem friendly enough to me"). They mean us to see the computer not as some foreign threat, but as an adjunct to individual authority. But by far the most ubiquitous and universally familiar 'personality' connected with personal computers is Chaplin's Little Tramp, usurped by IBM and resurrected in its most often-run ad managing a cake factory-which, despite economic hard times, is running at or near full capacity. Frosting with one hand, boxing with the other, this faintly androgynous reincarnation, toils innocently towards disaster in the form of an empty carton sliding down its beltway with the lid opening at right angles to those preceding. The situation is burlesque. In this imperfect meshing of man, cake and cardboard carton we are offered not the mature vision of Chaplin's Little Man in Modern Times, no longer footloose but tied to his job-literally clinging to his wrench and being drawn helpless through the cogs of the machinery; this is Costello without Abbot, Lewis without Martin, the fool in over his head with no one to come to his rescue. What is, perhaps, Chaplinesque is the ingenuity of the solution. The Tramp, stumbling backwards into an IBM office, accidentally touches the keyboard of a 
waiting computer with the tip of his cane. Stimulated, the machine lights up its screen and the Tramp, curiosity provoked, sits down, wriggles his fingers and, unaided, quickly causes an apparently delightful proposal for ending the chaos of production to be typed out on the adjacent printer. In managing our unwieldy fates IBM means us to see the personal computer as as vital to modern times as power brakes and power steering became to coping with the individual sedan and family wagon in the mid-fifties. Not our failure but the magnitude of our success necessitates this change, just as the growth of our vehicles and the Interstate Highway System required the incorporation of certain new mechanical advantages into our daily lives, to add muscle to our reflexes. There is, of course, contained in the need for a personal computer, the implication that for life as we have come to know it our nervous responses themselves are inadequate, all the way to the top of the system, to that most personal computer crowning our spinal column.

As re-coined, the term 'personal computer' is not proprietary to the International Business Machines Corporation, but generic to what are known as 'microcomputers.' Both terms are used to distinguish them from the bulkier 'minis' and much larger 'mainframes' from which they are, in a sense, descended. All derive from a common idea, and as do all modern classifications the definitions appear at times to leave gaps and more often to overlap-although after a while, as with Justice Stewart and pornography, you begin to know the difference when you see it. Even with a strip of black tape masking its corporate identity, the average person would no more mistake, say, a mainframe IBM 370 for an Apple II than he would a 747 for a Lear jet. But within a given collection of microcomputers (and there are scores of them) identifying the IBM without a peek at the logo would require a kind of sophistication boys once reserved for the seasonal variations in automobiles, the difference between two microcomputers as slight at first glance as that between the fifty-five and fifty-six Ford Fairlanes.

It is this discriminatory power I try first to develop.

"The problem really," she complains to friends, "is we can't talk. I get home, the baby wants to nurse, Sasha needs a nap, someone needs to fix dinner, and he's got his computer magazine rolled up in one hand just waiting for the change of guard. Or else he's off to try out another system. Sasha won't sleep. He wants to go to the 'puter store. After 
which he's grumpy all night because he's tired. I'm grumpy because I had to fix dinner. We fight over everything. All the time he's intoxicated with the possibilities of something that costs six thousand dollars and he thinks he can lease for a couple of hundred a month. How are we going to pay for it? It will pay for itself, he says. Or else he will line up a Saturday job. He feels he's entitled to that-maybe he is, except then he'll want to spend Sundays and nights and mornings before the kids get up with his head in the machine. He doesn't see it that way. But it's true, it is just a place to put your head when you feel like giving up on people. A good nap would work just as well. I can even see the difference when we're sitting on opposite ends of the couch and he's reading about them. When he reads a novel-which he doesn't have time for anymore-he's always looking up, quoting something, asking me what I think. We talk about it. I have the feeling I've read everything he's read. Not anymore. When he puts his nose into one of those computer magazines he is gone, gone, gone.... I think the house could collapse around our ears and he wouldn't notice. The kids are tearing the place up, bugging each other, crawling all over me. I feel like I'm alone. Now that I think about it, he's begun to act like one-not a kid, not a human being at all, a machine, a robot, according to program, without feeling. A computer has no feelings. I will not live with something, no matter how intelligent, that does not recognize human emotion."

The real_by which, in this era, we define the functional-difference between given microcomputers lies under the hood, inside the engine, what is known as the 'microprocessor.' Here, in general, ordinary people are prohibited from looking and tinkering by sheer reduction of scale. The making of a microprocessor is not so much 2 manufacturing as a photographic process. A circuit diagram the size of an apartment wall is optically reduced to the size of a snowflake and printed on the surface of a wafer of silicon crystal. What you see when you open a computer is not this 'chip' but a 'package' the size of a large caterpillar, whose sole function is to connect the microscopic circuitry at the edges of the chip to the broad paths on the circuit board which lead between the common garden variety of electrical parts, the transistors, resistors and capacitors, that in turn connect with the switches, dials and keys, the wall plug and, ultimately, human fingers. The practical lower limit on 
the size of a microcomputer is set by the scale of the human hand. The machine must be blunt enough to touch-just as our ideas, no matter how brilliant and finely conceived, must, in the process of realization, of coming into a common external light of day where practical use can be made of them, at some stage balloon to manual proportions. So, all but that portion of the machine commonly shown passing through the eye of a needle is devoted to making practical contact between man and machine-in the argot, to 'interfacing' the 'real world.'

While the kids are in the tub, while they're eating, while they're up to their elbows in Play-Doh (while Kathleen is at work with a world full of people up to their necks in problems) I'm up to my eyeballs in Info-World, Byte, Kilobaud, Interface Age, Dr. Dobbs' Journal and Personal Computing magazines uncovering the real differences between various microcomputers.

It is instantly apparent how the Defense Department runs over budget every time it contracts a new weapon. The original desire becomes the epicenter of invention. No matter where you begin, no direction or possibility is excluded. Nor is the limiting factor simply money. You can buy the Timex of microcomputers, the Sinclair for \$99.95. (In fact you can buy it from Timex, which holds world distribution rights.) The Rolex of microcomputers does not exist and probably never will. There is a certain level of craftsmanship involved in the production of the machine, but one that is attainable with modest diligence. It is not precision of touch and tolerance of fit so much as good design and rigorous inspection that insures a smooth-running microcomputer. Given a good diagram to photograph and reproduce, parts, subassemblies, finished products, are simply inspected over and over again (It is not the Swiss but the Japanese who set the industry standard) and the defective or substandard thrown in the scrap box. What distinguishes one product from another is commonly not ultimate performance of design but of assembly, which relates to the rigor with which these inspections are performed and the common standard enforced. Finally, this is not a function of Steuben-like artisans bent over raw crystal but of corporate accountants stooping to inspect the bottom line. As many microcomputer companies are still run by men who designed the product that launched them, standards of inspection remain commonly high, while the balance sheets tend to be shaky. Like the aircraft industry before World War II, the auto industry before World War I and the textile industry before cotton became king, the computer industry awaits the 
clear emergence of its dominant inventor, its Whitney, its Douglas, its Ford.

Still, there is something like a bottom rung, a minimum plateau of performance. While a handful of serious products are available for less than sixteen hundred dollars, at that level of expenditure something like a quantum leap in performance occurs. IBM's price is no accident, although for the money it seems I would be better off not buying an IBM. What you get from IBM is a sixteen-hundred-dollar calculator with potential for growth. (That little dagger begins to penetrate.) As it comes off the shelf, the sixteen-hundred-dollar IBM Personal Computer is literally an enigma; there is no way to divine what it is thinking. The green television monitor is an extra three hundred dollars, two if you settle for black-and-white and anywhere from three to ten times more for full color. You can attach it to your television set, but the effect is one of reading a book through a fishbowl; only those images in the central third of the screen will be rectilinear. At sixteen hundred dollars storage is on cassette recorder and you get only sixteen kilobytes of RAM on a system designed to run half a million. The extra memory is a thousand dollars, as are disk storage and a printer; the asynchronous interface necessary to communicate with things like The Source or Dow-Jones Information Retrieval or with other IBM's is several hundred, the circuitry that produces the color graphics several hundred more. What you get for sixteen hundred dollars is something like a stereo amplifier-no speakers, no turntable, no tuner, no tape deck, just a very powerful amp, the potential center of a much larger system. In fact, as described in the ad the IBM Personal Computer would cost not sixteen hundred but over six thousand dollars, or would if you bought IBM components. No one I speak to knows where I could get non-IBM components. Like drugs: "they're around," I'm told, "you just have to look."

Where I see these things advertised is in the trade publications. Memory expansion kits, color enhancement boards, hard-disk controllers are to be had through the mails. I'm reminded of the hot rod magazines of my youth, of Headman headers, Holly carbs, Moon disks, progressive linkages, transmission adapters, made to 'bolt on' or 'plug in.' I never actually saw or touched these things. It was not simply that they cost tens, even hundreds of dollars; it was a matter of destiny. I had grown up a member of that class of people forbidden to work with machinery and which included all women and any man of tested 
intelligence. We were not forbidden to know how things worked, simply excluded from certain practical_and therefore real_experience. ('Shop and woodworking' in the parlance of counselors and parents were synonymous with degeneracy.) From erector sets to chemistry sets, towards the increasingly abstract, physics, philosophy, and literature, I was led, in the belief that in that direction lay control of my fate, in the ability to manipulate not wrenches, torches and lathes, but concepts, languages, ideas. I did build hot rods, but only as mental constructs. Baroque images of interwoven exhaust manifolds, of butterfly valves opening in synchrony, of gummy tires on reversed rims, of pinstripes and metalflake paint remained just that, images. Like California, they were part of a future I shared without ever really experiencing, something perfected without ever having been practiced, something I eventually abandoned to obtain the respect of those whose opinion of the future we valued more highly than our own. In a sense, a whole generation of men exists who possess no rational objection to the personal computer, for whom it is the ideal synthesis of all they were forbidden and all they have been led to desire.

A hot rod for intellectuals!

In theory it is possible to take any computer, not just the IBM, bolt on and plug in your own equipment, and have, well ... capability. Capability in the Abstract-which is not the same as power. In the Atomic era, having reached the limits of Power, we have drawn back at least temporarily, seeking to control that power, to manipulate it toward definable ends. The computer is the tool of limitless and fluid definition, the instrument for rationalizing power, just as the automobile was the instrument for rationalizing space, the means to take each of us as far as fast and in whatever style of comfort we could imagine. And just as it was possible to customize an automobile, so too with the personal computer, it is possible to fit the instrument of control to whatever concept of absolute capability we can imagine. Memory is no longer the problem it once was; the price of memory is down to a buck a thousand characters and falling steadily. Mass storage is even cheaper, mini-floppies, mini-Winchesters, full-sized hard disks available for a few thousand dollars. In practice it would be possible to start with a Timex-Sinclair and have a thirty- or forty-million-character data bankmore than anyone except the Pentagon could afford up until ten years ago-for a few thousand dollars.

Then there is the matter of the engine, the microprocessor to the 
computer as the internal combustion motor to the hot rod. The microprocessor is the engine of logic, the ultimate power of any computer governed by the potential built into that initial design from which the first photograph was made. Souping it up, thwarting certain design features in order to enhance others-the boring and stroking, if you will, of a given microprocessor-is not that easy. As the reciprocating engine must valve and time and fire and cycle in an orderly fashion, so too the engine of logic, the microprocessor, must observe strict time, opening and closing its valves, or 'logic gates' only in certain order and combination at the proper moment, cycling and recycling, its ultimate power inherent in the speed at which it can move a given mass of information in a single complete cycle. This power is inherent in the original design of the chip-in that photograph on the wall-but it may not find full use in the computer it must ultimately drive. Off the shelf, stock computers, like stock automobiles off the showroom floor, display only hints of their true potential. To achieve that, to wring the last byte, to rev the processor out to the last herz, it is necessary to bolt on high-performance equipment. More important, it is necessary to select the right engine to begin with.

One of the problems with the IBM was that its microprocessor was not an IBM at all but an Intel Corporation 8088. Computer people (as with hot rodders, I included in this category not only those who designed, programmed, sold, owned or used the things but also the dreamers, the readers of the literature-other than myself) appeared skeptical, even indignant about this crossbreeding, much as certain Pontiac owners a few years back were outraged to find Chevrolet motors under their hoods. There was the suggestion IBM was being cheap. Always before they had developed their own processors; why the sudden switch? A second school of thought was that the choice of the Intel chip, third-generation descendant of the original computer-on-a-chip, the 8080 , was a landmark concession on the part of IBM to an industry-wide formula not of their own making, a capitulation on the order of national metric conversion. Still, there were fundamental objections of those who doubted the potential of the 8088 as an advanced engine. Microprocessors move information the way roads move traffic, on a 'data path,' commonly two, four, eight lanes wide. One of the first sixteen-lane, or 'sixteenbit' microprocessors, the 8088 as a logical descendant of the 8080 still shared much of the architecture of that chip-that is, under a microscope, close inspection would reveal portions of that older design 
incorporated in the architecture of the new processor. Although lost at first amid the newer, wider sixteen-bit tracery, these older circuits are still there and have to be run. The 8088 processor has to 'think' at times in an old-fashioned eight-lane way. While this makes it compatible with older machines and the established way of interfacing - that is, hooking up the processor to perform useful work-it also makes this implementation more baroque. There are other computers in the works that make use of totally new sixteen-bit processors like the Motorola MC68000, or thirty-two-bit processors, or, it is rumored, sixty-four-bit processors (a data path sixty-four lanes wide) with more elegant logic and vastly greater potential, and it had been suggested in many places that people considering the IBM might do better to wait. Six months, a year-things move that fast-something better would be along at the same price.

Thinking computers might play a role in my future, I had once taken a data processing class in college. The most sophisticated piece of equipment actually used in the class was an overhead projector (based on the Fresnel lens and mazda lamps-that is, the technology of the lighthouse). My personal equipment consisted of a green plastic template for tracing the lozenges, loops and arrows of a logic flowchart and a number 2 Eberhard Faber pencil. To get your hands on a real computer you had to take Data Processing 3 (for some reason, there was no DP-1). The one time we actually went to see a computer in operation, disaster struck.

I had been standing for some time in the room adjacent, where advanced students in white lab coats were spreading flowcharts the length of cafeteria tables and muttering alchemically to themselves and one another about bugs and glitches and various sorts of sorts (bubble, heap, tree) and time (run time, machine time, real time) while alphabetically, one by one, members of the class were ushered through double doors marked AUTHORIZED PERSONNEL ONLY BEYOND THIS POINT. I remember someone bumping into me with a trayful of IBM cards and looking stunned, as if she had made a wrong turn and encountered a wall where there should have been a corridor. Just as I reached the doors to the computer, my instructor appeared in a lab coat with his name embroidered on the breast pocket, his face stitched with grave concern as he blocked me across the chest with his forearm and whispered urgently, "The system just crashed." This announcement touched off a silent frenzy among those who belonged there and a kind of helpless panic in the rest of us as we tried to get out of their way 
without stepping on some chart as it slithered off the table-all the while trying to get a glimpse through the flapping doors of the wreckage in the other room.

Later, when I was teaching, it was customary to list the times of certain individual study sections in the schedule of classes as TBA-that is, To Be Arranged. These were not classes but what might be traditionally called tutorials, a student and a professor working together by mutual consent, informally. But, having gotten everything else onto the computer, the payroll, benefits, library catalog, materials inventory, and telephones, when it inevitably came time to incorporate registration and scheduling, word arrived from the office of the president that we would have to stop announcing classes as TBA because the computer did not like TBA. TBA crashed the system-that is, the ambiguity of it did for the computer what swallowing a seagull will do for a jet, what declining to shake his hand will do to a political candidate-robbed it of power and induced the logical equivalent of a stroke. Encountering a TBA, the University computer locked its keyboards, cleared its screens, stifled its printers and entered an autistic phase that could only be cured by pulling the plug.

Something like that befell my efforts to acquire my own IBM. Unable to substantiate a reason more fundamental than Kathleen's for objecting and under expert admonition to wait, I became depressed. I felt I was being tested according to some Victorian formula. Given time (unspecified) I would change or the machine would change and thus our wedding would be prevented.

It is not, after all, the fault of the machines, our archaic mistrust, our impossible demands. It is their very uncomplaining nature that makes our vehicles, our appliances, our tools revolutionary, that permits us to control them effectively - and through them to control large and mainly impersonal forces. We use them in ways we could never use the horse, the ox, or each other. A good tool is the perfect mating of knowledge to the requirements of reality, of principle and the desired effect. A tool is not created for the purpose of making anyone feel more human through empathy, sympathy or sentiment; it is not an extension of the soul but of the reach and grasp of the practical mind. True, it seems we are beginning to reach into certain areas and grasp certain things previously inaccessible. We have no protocols to govern these new machine-human intimacies. It is not the tool itself, however, the "hardware,' but the leverage on others it gives certain people that is undesir- 
able. I do not mean to fall into a sort of oxymoronic computers-don'tkill-people, people-kill-people way of thinking. But a computer without a program is like a pistol with no bullets in it (or a car with no gasoline), an inert object, an industrial museum piece. It is the program we encounter, in the same way we encounter the character of a human being. All that is repulsive in the current embrace of personalized solicitations, chatty bank statements, semi-encyclopedic credit histories and book-length grocery receipts is the idea we are in the process of being understood by something or someone we will not be allowed to understand in return. What's so nightmarish about Arthur Clarke's HAL 2000 is the one-way street of its understanding; of itself this is not inhuman, it is the perpetual bonhomie of the politician, the salesman, the convention, the marketplace, presumptuous, inescapable. What is missing is the man or woman behind the mask. Consequently our power to make a stink, create a scene, blow our cork, cut someone dead with an acute observation (or a sharp knife), beg their pardon or excuse ourselves is short-circuited. Tears, shouts, fainting, sarcasm, wit, have no power to abort this electronic process of understanding. In fact, a whole thesaurus of human strategies for signaling inappropriate behavior in others no longer serves us in our daily lives with machines. Civility enforced, thrown back upon our own mercy, to be or not to be, nothing more, we self-destruct.

"That's what I hate most," Kathleen concedes. "Even when it talks gibberish I come away feeling it's not the machine, it's me-I'm the dumb one. If we all showed that sort of response to people I sometimes think we would begin to make real human progress.'

It is this, finally, her irrational trust in some illogical human need of mine, that unexpectedly clears the way... almost. I am forced to concede that ours (also known as a 'home computer') might better live across the yard with the other tools, far enough away for tax purposes to place it outside that undeductible category although still not far enough for Kathleen, who is both more demanding and less vague than the IRS about what does and does not constitute a legitimate use of her home. However, at that distance it will be mine, personally, and with it personal satisfaction, personal pride, and personal responsibility. (This, in my case, takes the form of guilt, which, despite the efforts of some of the best minds of the century to make it transferable, remains mine alone.)

A final concession: for the sake of economy, it is not to be an IBM. 
At sixteen hundred dollars what the IBM is, I decide, is a white elephant; to realize even a fraction of its ultimate potential would break us. Instead, I pick something I think we can live with and only at the last moment begin to sweat. Do I really mean to do this? Standing in a room filled with computers and printers, suddenly I notice people doing their calculations in longhand on old-fashioned salespads, the kind with the carbon leaf you have to keep shuffling. Unnerved, I feel morally committed. I scratch the desk like a poker player signaling the dealer to hit him one more time. (It takes longer to fill out the purchase forms than it does to call Idaho and check my credit-I was once in Idaho during the war; I am there now because the bank's computer is there holding a pound of my electronic flesh.) Free, I will be getting one operating manual, two hundred and sixty pages on what to do after you plug it in, one BASIC Programming for Beginners manual-three hundred and forty pages, one loose-leaf ring binder containing a word-processing program and manual (sixty pages) and a five-part taped program of instruction. Finally, although he is not supposed to do things like this, my salesman, in a gush of humanity, throws in a pair of cassettes worth five bucks and we shake hands.

"I have thirty days to get my money back. If, at any time during those thirty days, the computer threatens to destroy us," I guarantee Kathleen at the back door, "I will take it back without argument." When she makes no move to block me, I enter and open the box to show her.

"It's gray," is all she says.

Ours is an old house and the three-prong plugs on the machine will not fit the receptacles. We have two or three adapters but I can't remember where I've put them. After searching the house three times from end to end, I grab some lamp cord and a pair of wire strippers.

"What are you doing?"

"Putting a different plug on it."

"If you cut the plug off it they will never take it back. Why can't you just wait. Tomorrow you can buy an adapter."

I have not come this far to wait; instead I rewire the receptacle with a modern socket I've had nearly a year. When I find the right switch, the screen lights up with a series of prompts and finally flashes me the READY sign.

"Now what?" 
"You begin. Programming it to do what you want."

"I want it to leave me alone," she says. Then, "You don't know anything about programming."

"I plan to learn," placing my hand solemnly on BASIC for Beginners.

"When will you find time?"

"I will make time. Plus, the computer will save time." I feel like the President defending his budget. "It will balance the checkbook."

"It takes about ten minutes a month to balance the checkbook-that is, once I can get you to sit down with me."

"I don't like to sit down with you because we get into an argument every time. If nothing else," I argue, "the computer will save us time wasted arguing."

"What if the computer is wrong?"

"The computer is never wrong, unless it is given wrong information."

"Well, what if I disagree?"

"That probably would mean you had made a mistake. But why not just wait and see?"

"I've already seen enough. I want it out of my house. I want to balance my own checkbook. I don't want to argue with anybody or anything; I want to play with the children, I want to see you for a while."

"I'm right here."

"I want to see your face."

"I just want to run the word-processing program once and see how it works. It will just take five minutes."

An hour later I am still engrossed in trying to make it work. For some reason it refuses to make tapes-literally, stops and says TAPE BAD. As instructed, I change the volume settings on my recorder. It still insists: TAPE BAD.

"I don't want to hear it," Kathleen says. "I just want it out of the house by morning."

Next day, over the phone, my salesman (who repeats, he has no experience with tapes) says he'll have someone get back to me right away; over the next three days I am put in touch with a half-dozen people who have obviously read the same manuals I have and who have nothing to add. The machine phlegmatically insists TAPE BAD. At one point I go back and buy a new cassette recorder, one designed specifically for my computer-another sixty dollars, comes with cable, so now I have two. TAPE BAD-the computer sticks to its guns. As I prepare 
to concede defeat and pack the whole thing up for a refund, the phone rings. Someone named John wants to know what color the tape is? The ones I was given free are all red labels, I tell him, Realistic HighQuality. No good. He says I need digital quality. So, out I go to buy Certified Leaderless tape-five dollars each-and a nine ninety-five paperback on Programming the Z-80, the microprocessor that drives this and half the other microcomputers in the world. The computer promptly blinks its asterisk and acknowledges TAPE OK.

I can't help feeling myself on the brink of some valuable discovery, not just intrinsically worthwhile but valuable the way pyramid schemes and chain letters are to those who get in very near the beginning-the way IBM hopes the expanding personal-computer market will be for it. Being able to control those who follow by virtue of dominant position, being top dog, is not, however, what I want most. I want something more than my personal franchise in the electronic marketplace; I want what I had wanted the first time my wife threatened to leave me, when, shortly after the children were born, I brought up the idea of reentering the Church. I want to believe in the computer the way America believed in Ford, the way as a boy I believed in the flag and in God-not Christ, but God the Father-symbol of an omniscient authority whose power is pervasive, like gravity, holding everything together from the center. I want to be taken personally into account in the formulation of the Future so that I might have an inkling once more of a truly personal Fate, rather than find myself trapped in some manufactured Destiny on the thirty-first day after I've bought it.

"It will keep track of stock portfolios, stamp collections, the progress of various fitness routines, the contents of our freezer, monthly bills, loan computations, the daily temperature and barometric pressure. There is a program for a tachistogram to improve reading speed. We can get the newspaper delivered electronically. We can send a letter electronically. We can do biorhythms-"

"Show me," she says.

Like most microcomputers, as more lines are added to the screen it begins to scroll the electronic page upward, holding what will not fit on the screen in memory; it is like obseving a very tall object through an elevator window. But then, so is the actual process of reading and writing, attention not to the whole but to the sequence of parts. It is precisely the fact that we cannot see everything at once, only certain details in serial order, that makes reading compelling, what's going on 
off-screen as peripheral to comprehension as what's going on in our subconscious.

It takes three days to get the biorhythm program running correctlythe matter of a comma that should have been a semicolon. "But now the work is done," I tell her, "and I'll never have to do it again."

We were given charts as a wedding present. Now we are thirty-six hundred days older-I am pushing seventeen thousand-the computer delivers no evidence of stress, past or present, or of impending disaster in our lives. We both note on a chart of her mother's rhythms that the twenty-fifth will be a potentially calamitous day, then we guiltily stuff her chart on a shelf. (Months later we discover the children shredding it with scissors and as Grandma is still alive and well there seems no point in yelling.) Anyway, I boast, I can reproduce the information if necessary in minutes-though I doubt I will for at least another ten years. The children are indifferent, as always, to this close brush with discipline and to the special nature of their salvation.

"The real problem is the whole thing is so new," I reason, "that there aren't any programs to do the things we really need done, all the boring, repetitive, time-consuming domestic chores." For cooking, cleaning, washing clothes, we'll have to wait for the robots-although we can have the computer turn the appliances on and off for a few hundred dollars worth of hardware.

"Then what can it do?"

My first original program is composed in BASIC (short for Beginner's All-purpose Symbolic Instruction Code), a high-level language. The logic symbols resemble, at times, plain English, words such as AND, OR, IF, THEN, ELSE, HALT, STOP, PEEK, POKE and CONTINUE. Unfortunately, words more common and crucial to a typical set of instructions are borrowed from some form of computer Esperanto: GOSUB, DEFINT, INKEY $\$$ and TRON. Harder to grasp are outright concoctions such as CHR\$, ASC(n) and VARPTR. Each represents a single command. By stringing them together skillfully one can maneuver information through the machine, down the data path, as a veteran drill sergeant would a column of men down a narrow street. (To my amateur cadence-call things proceed in less orderly fashion.) In the computer's vocabulary, as in common language, there is also the allimportant matter of punctuation - which had held up the computation 
of our biorhythms. A computer's concern for the proper placement of commas equals or exceeds that of the most demanding professor or editor. While trying to get it to accept a line of code without flashing a SYNTAX ERROR I begin to feel like James Thurber confronting the electronic ghost of Harold Ross. My eyesight begins to fail, the little points of light of which the letters are formed on the screen begin to dance and dissociate, like molecules in Brownian motion. Unable to solve the mystery of how to punctuate a particular instruction, I resort to simpler, more extensive locutions-less and less do I see evidence of central intelligence on either side of the screen. Apelike, I spend minutes studying the semicolon on the keyboard before tentatively giving it a poke with my finger; then I lavish equal time on the altered pattern on the screen. To this electronic universe there is no more definable center than there is to a balloon, within the ever-expanding membrane of logic no more evidence of inspirational order than in the way a fat phone book manages to contain all our names, or a novel all the volatile huffings and puffings of our modern lives.

Still, when I've finished I can hardly wait to demonstrate.

First, the word READY pops up. "That's called a prompt," I explain. "The machine is 'hand-holding.' Not the machine, the operating system, the control program, leading us by the hand, step by step, through all the essential startup procedures by eliciting the proper responses with a series of prompts. It's really the programmer, wherever he, she or they may be now, guiding us in absentia. "So we've loaded the program 'PLANETS' and now we want to run it," typing R-U-N and pressing a white key labeled ENTER.

Immediately the screen begins to fill with tiny mosaics of light, slowly defining an onion-shaped void in the center.

"Outer space," I have to explain. "My approximation. You see, a faster clock would create a faster fill. I think the manufacturer is just being cheap. They could put in a faster chip, change a few circuits and hold the price-line. It's just corporate inertia-plus they leave themselves room for the 'New Improved Model' next year, the way they did this year with extra RAM-" pointing as one small mosaic breaks suddenly away from the others, winking across the middle of the screen through the void, erasing some of the white before vanishing to reappear several lines higher, backtracking.

"Is that all?"

What seems elementary becomes extensive when programmed into 
the machine, the way the inventory of a small shop expands to fill the many pages of an advertising supplement. The computer itself is not an instrument of summary-this is an illusion no improvement in speed will ever convert to reality-it can only operate on an exhaustingly elaborate plan full of infinite logical gates, and-ing, or-ing, yes-ing, no-ing, equating and refusing to equate what it encounters in the way of facts and assumptions. Like corn shot from a gun, every grain of discovery swells to new proportions.

"It's enough for a start."

"How long did that take you?"

"Two days. That's not the problem."

The problem as I see it, is one of language. BASIC is not basic enough. Like English, which it endeavors to mimic, BASIC invites ambiguity. The attempt to extract greater power from a language, like that to milk more horsepower from a given engine block, is rhetorical and ultimately strains the material: meaning. Long before reaching the operational limits of the microprocessor, the programmer reaches the limits of his ability to communicate. Having first abandoned thoughts of eloquence, he finds himself ultimately confronting things that cannot be said at all. As the grotesque appearance of a hot rod results from bolting on various appliances in order to thwart mechanical shortcomings, the baroque nature of a computer program results from the need to constantly apply circuitous logic to the inherent indirection of the language. In the process of assembling BASIC, of borrowing and bolting together a beginner's lexicon, concessions have been made to time, to clarity, to the operator, the human, at the expense of the machine. It is languagenot the keyboard, not the video screen-through which the operator comes face-to-face with the machine, between the two, the interface, again: gossamer meaning. Computer language is, itself, a form of hot rod, not simply for but of the mind. It is a logical arabesque within which, beyond some electronic vanishing point, through Eliot's unseen, once-known gate, Meaning passes in and out of Being. Words become sculpture, Art becomes Life-as with art, with the computer the creator is absent, as the author is from the reading; the philo- and onto-genetic processes go forward without him, except as he is contained in his language. Or languages-for computers there exist a number of common tongues: FORTRAN, COBOL, PASCAL, FORTH, LISP, SAIL, LOGO (each conceived as a more direct logic for the problems its creator wished to set for his computer) for mathematics, business, 
science. Where these categories often overlap, however, their languages do not. The operator cannot, if the feeling moves him, or necessity compels, sprinkle his program with gallicisms. Computers are serial polyglots; they speak many languages, but only one at a time. They cannot interpolate except at the lowest level and the operator is compelled to translate into the next lowest common denominator of meaning.

Beneath BASIC-indeed, beneath all dialects-is a proto-language, a machine language, unique to each microprocessor but descended from digital computer Ur-sprach, the ones and zeros from which all electronic logic springs, binary code. Just before my thirty days are up I complete my second program, a Z-80 machine-language program which types address labels for Christmas cards. While the BASIC program took up one column on a single page, the new program, containing several thousand instructions, is the length of a modest essay-an essay that is intelligible in its arguments only to other programmers and to the computer; any quality of thought, of logic, contained within is appreciable only in the performance of the machine in its set task.

In this particular case the return on my time is improved. While it takes a month of afternoons and one whole Saturday to get it working, the program executes in seconds, limited only by my ability to feed envelopes into the printer. It saves two hours of tedium and perhaps a day's worth of sentimental rehashing of feelings and argument over who we should or should not renew contact with. Afterwards we have no idea who got a card and who didn't, although I suppose in the future I could punch them all up in a few seconds on the machine if it ever seems crucial to recall.

The frustration, the fascination and final disenchantment with computers is no different or greater than that I had experienced with Science, the automobile or Picasso. What seems a door to the universe, the vehicle of great adventures, the expression of a truly personal vision, becomes over time inversely, the butchery, the uprooting and diversion of human concerns into infertile regions, a form of self-absorption. The computer disciplines its owner-operator to language, logic, the volume and shape of thought as the airplane does the flier to the volume of space, the hot-rod mechanic to the bore and stroke of the piston. As a device for converting human energy, for achieving mental advantages, the personal computer is, perhaps, the ideal engine, capable of propelling us through its element, logical process, at rates often far in excess of its progenitor, the brain. As an instrument of comprehension, however, it 
is ultimately a kind of rococo model of the mind, one, like all lower forms, content with being rather than anxious for meaning. It is an object unlike a human, unself-motivating, whose special powers are routed, finally, not through life but through a single switch I find some dark satisfaction in turning off. 